\title{
Application of HPLC to Study the Reaction of Free Radicals with Antioxidants and/or Toxins
}

\author{
Paweł Piszcz, Konrad Żurawski, and Bronisław K. Głód \\ Department of Analytical Chemistry, Faculty of Science, Institute of Chemistry, Siedlce University of Natural Sciences and Humanities, \\ 3 Maja 54, 08-110 Siedlce, Poland \\ Correspondence should be addressed to Bronisław K. Głód; bkg@onet.eu
}

Received 16 May 2013; Revised 22 December 2013; Accepted 5 January 2014; Published 13 February 2014

Academic Editor: Aicheng Chen

Copyright (C) 2014 Paweł Piszcz et al. This is an open access article distributed under the Creative Commons Attribution License, which permits unrestricted use, distribution, and reproduction in any medium, provided the original work is properly cited.

\begin{abstract}
The application of HPLC in the antioxidative (antiradical) properties studies of various samples is discussed in this paper. The assay is based on the reaction of, characterized by strong oxidizing properties, hydroxyl radicals (generated in the Fenton-like reaction) with the sample and with the, so-called, sensor. The product of the sensor reaction with the radicals is analyzed using RP-HPLC with fluorescence detection. It is well known that antioxidants, which are healthy for living organisms, have a negative environmental effect. Therefore, the goal of the paper is to discuss if the same setup can be used to get rid of unwanted compounds (toxins) from the environment. It was found that the phenols and PAHs are degraded by hydroxyl radicals. The optimal (maximum degree of the degradation) conditions were obtained for $\mathrm{pH}=3.0$ and $0.1 \mathrm{mM} \mathrm{Fe}{ }^{2+}$.
\end{abstract}

\section{Introduction}

In general, free radicals are more reactive than other chemical species [1]. Most of all reactive and strong oxidants $\left(E^{0}=\right.$ $2.31 \mathrm{~V}$ ) are hydroxyl radicals [2]. They are involved (as a reason, result, or side effect) in the various diseases [3]. Their beneficial role in the environment comes from their reaction with toxins. Living organisms have developed many effective defenses to protect themselves from free radicals. Among them are antioxidants-substances (compounds) that in small amount inhibit the oxidation of other, usually biologically active, compounds. It is commonly assumed that oxidation is induced by oxygen, free radicals, or, more generally, reactive oxygen species (ROS). Therefore, sometimes the term antioxidants is convertibly used with the term "free radical scavenger." Usually, antioxidants are health benefit compounds. Therefore, the consumption of food rich in antioxidants decreases the risk of many diseases. Many techniques [4], including HPLC [5], can be used for the analysis of antioxidants. Often, it is difficult to analyze all of them because of their interactions and unknown sample composition (food products or blood serum/plasma). Therefore, it is much more convenient to measure the total antioxidant potential (TAP) of the sample, which is defined as the sum of products of concentrations of all antioxidants in the sample and their rate constants [6-8].

It is usually assumed that free radicals have negative influences on living organisms, while antioxidants are health benefits [9-11]. Often, their influence on the environment is just the opposite. Many methods can be used to remove harmful components (phenols, pesticides, polyaromatic hydrocarbons (PAHs), etc.) from the environment, among them the free radicals [11]. Specially, highly reactive (strong oxidants) hydroxyl radicals are the topic of the current interest for the destruction of organic pollutants in surface, ground- and wastewaters as well as sludge cleaning [12-16]. Because of the high standard redox potential they induce nonselective oxidation processes, even of very stable compounds.

The total antioxidant potential (TAP) is usually determined at "biological" pH (7.2). However, in the human body (e.g., in the gastrointestinal tract or in the inflammatory conditions) the $\mathrm{pH}$ is not constant. Previously [17], it was demonstrated that hydroxyl radicals can be used for the TAP determination. The advantage of this assay is the ability to perform measurements at a different $\mathrm{pH}$. The paper describes (i) the application of the described assay to the degradation 
of toxins and (ii) the influence of experimental parameters, especially $\mathrm{pH}$, on the process efficiency.

\section{Experimental}

2.1. Instrumentation. Measurements were performed by means of a chromatograph comprising an Interface Box, 4-channel Smartline Manager 5000 with Degasser K-5004, Solvent Organizer K-1500, Dynamic Mixing Chamber, HPLC Pump Smartline 1000, Autosampler Smartline 3900 (all from Knauer GmbH, Berlin, Germany), Smartline 400 Column Thermostat (Industrial Electronics, Langenzersdorf, Austria), and RF-10AXL fluorometric detector (Shimadzu, Tokyo, Japan). Samples were separated on a Eurospher RP$185 \mu \mathrm{m}, 250 \times 4 \mathrm{~mm}$ I.D. (Knauer, Berlin, Germany) column. System has been controlled and data acquisition performed on the IBM PC type computer with Eurochrom 2000 and Clarity Chrom V 2.62007 software. pH was measured using pH-meter OP-208/1 (Radelkis, Budapest, Hungary) with OSH 10-10 electrode (Metron, Czekanów, Poland).

2.2. Reagents. Gallic, 3,4-dihydroxybenzoic (3,4DHBA), $p$ hydroxybenzoic ( $p$-HBA), sulfanilic, $m$-coumaric and $p$ aminobenzenesulphonic acids, iron (II) sulfate (VI), hydrogen peroxide, phosphate buffered saline (PBS) tablets, and HPLC grade methanol were obtained from Sigma (St. Louis, MO, USA). Other acids (sulfosalicylic, Fluka, Buchs, Switzerland; salicylic and acetylsalicylic, POCh, Gliwice, Poland) were of Analytical-Reagent grade and were used without further purification. Water was three times distilled from quartz apparatus. Mobile phases were filtered through a $0.22 \mu \mathrm{m}$ membrane filter (Millipore, Bedford, USA). Certified solution of $10 \mathrm{ng} \mu \mathrm{L}^{-1}$ benzo[a]pyrene (B[a]P) was obtained from Ehrenstorfer, Augsburg, Germany.

2.3. Materials. The different, commercial types of coffees (Jacobs Krönung, Cuban Arabic Toffee, Indonesian Arabic, Tichbo Familly, Gala, Woseba Strong) were purchased from the local supermarket.

2.4. Procedures. Hydroxyl radicals were generated through Fenton reaction by $7 \mathrm{~min}$ incubation of $1 \mathrm{mM} \mathrm{Fe}^{2+}$ and $0.03 \%$ $\mathrm{H}_{2} \mathrm{O}_{2}$ in $50 \mathrm{mM}(\mathrm{pH}=7.4)$ PBS in the presence of $1 \mathrm{mM} p$ $\mathrm{HBA}$ at $37^{\circ} \mathrm{C}$. These parameters have been optimized in our previous paper [8] as enabling the achievement of asymptote of the constant concentration of $3,4 \mathrm{DHBA}$. The same reaction was repeated with the analyzed sample. It means that both the sensing compound and the analyte scavenged the radicals. Product of the reaction of hydroxyl radical with $p$-HBA, namely, the 3,4DHBA acid, was detected using HPLC with fluorescence detector. When the sample was added to the reaction mixture, it decreased the area under 3,4DHBA peak due to the competition reaction with radicals. If the analyte reacted quicker than the sensing compound, generation of the $3,4 \mathrm{DHBA}$ was decreased. This assay enabled the comparison of the hydroxyl radicals scavenging performance of various substances, measured as a decrease of area under 3,4DHBA peak. The degradation was examined using the described above Fenton reaction, to the generation of free radicals.

Chromatographic experiments (TAP measurements and concentrations of the degraded compounds) were performed using HPLC with the fluorescence detection and a flow rate of $1.0 \mathrm{~mL} \mathrm{~min}^{-1}$ at $25^{\circ} \mathrm{C}$. The column was stabilized at $25^{\circ} \mathrm{C}$ by passage of mobile phase for $1 \mathrm{~h}$ prior to the chromatographic measurements. A $100 \mathrm{mM}$ phosphate buffer $(\mathrm{pH}=6.6)$ with 2 vol.\% methanol was used as a mobile phase. $10 \mathrm{mM}$ stock solutions of the analyzed compounds were prepared in the triplicate distilled water from quartz apparatus and diluted to the required concentration before use. Samples $20 \mu \mathrm{L}$ were injected using the autosampler. The output signal from the fluorescence detector was continuously displayed on the computer screen. Excitation/emission wavelengths were $270 / 310 \mathrm{~nm}$ for $3,4 \mathrm{DHBA}, 295 / 410 \mathrm{~nm}$ for $\mathrm{B}[\mathrm{a}] \mathrm{P}$, and $270 / 358 \mathrm{~nm}$ for other compounds.

The coffee extracts were prepared by infuse of $10 \mathrm{~g}$ of sample in $100 \mathrm{~mL}$ of water $\left(90^{\circ} \mathrm{C}\right)$ through 10 minutes. Then solutes percolated by Milipore filter.

Every sample was injected three times and the average was taken for further elaboration. The TAP measurements were related to the mean value of the control sample, containing no solute.

\section{Results and Discussion}

Several modifications of TAP assays, based on HPLC, are already described in the literature [5]. Generally, they are based on hydroxyl radicals generation by the Fenton reaction, followed by their reactions with so-called sensor (in our case $p$-HBA). Product of this reaction has been analyzed using HPLC. Analyzed sample (pure compound, food product, blood serum, etc.) decreased area under its chromatographic peak because of the competition reaction between sample or sensor with the radicals. TAP can be expressed as decrease of area under peak of the reaction product of the sensor with the sample. Various analytical parameters (column and/or chromatographic system: reversed phase, ion exclusion, porous graphite; sensor: phenylalanine, salicylic, $p$-hydroxybenzoic and terephthalic acids; mobile phase: concentration of organic solvent, $\mathrm{pH}$; detector: photometric, electrochemical, fluorescence, MS) were tested to obtain optimal conditions for the separation and detection. Furthermore, the following Fenton reaction parameters were optimized: reaction time, concentrations of the sample and sensor, and temperature [8]. The greatest advantage of this assay is to demonstrate the possibility to conduct the measurements at different $\mathrm{pH}$ values. Therefore, the influence of $\mathrm{pH}$ on (i) the hydroxyl radicals generation, (ii) the hydroxyl radicals reaction with sample and sensor, and (iii) analysis of 3,4DHBA will be discussed in the present paper. The application of elaborated assay to the toxins degradation by the hydroxyl radicals and the parameters influencing this process will also be discussed.

The applied TAP assay is based on the hydroxyl radicals generated in the Fenton reaction. The $p$-HBA is used, as a sensor, for the hydroxyl radicals detection. The TAP measure is the decrease of area under 3,4DHBA peak. All reaction 


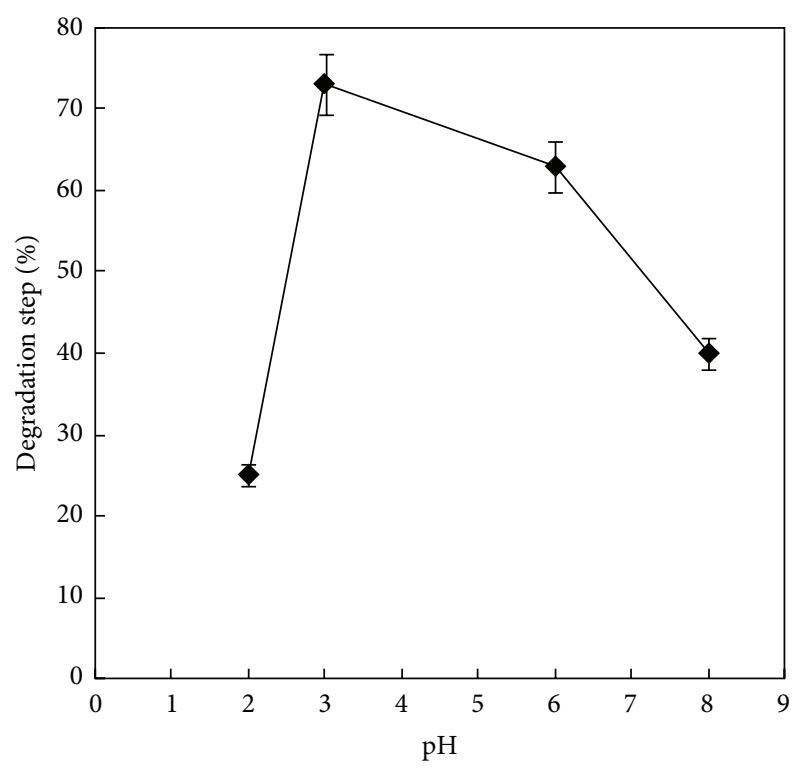

FIGURE 1: Effect of $\mathrm{pH}$ of reaction mixture on the degradation step of $p$-HBA.

parameters, except $\mathrm{pH}$, were optimized [8]. The influence of $\mathrm{pH}$ on the decrease of the $p$-HBA peak is presented in Figure 1 . In this case $p$-HBA was used as a model compound to test the possibility of degradation of phenolic compounds by hydroxyl radicals.

The simplified Fenton reaction can be expressed as follows [18]:

$$
\mathrm{Fe}^{2+}+\mathrm{H}_{2} \mathrm{O}_{2}=\mathrm{Fe}^{3+}+\mathrm{OH}^{-}+\cdot \mathrm{OH}
$$

It follows, from the above equation, that the $\mathrm{pH}$ reduction shifts the reaction to the right. The antioxidants, sensors, and toxins are usually the weak electrolytes. Their step of dissociation is also $\mathrm{pH}$-dependent. The electrochemical studies [19] show that the dissociated forms of electrolytes are more easily oxidized than undissociated ones. It seems that a similar relationship should refer to the oxidation process caused by hydroxyl radicals. This means that $\mathrm{pH}$ influences both, the yield (efficiency) of hydroxyl radicals generation in the Fenton reaction and the reaction between these radicals and sensor and/or sample. Therefore, do not expect a simple correlation between the degree of degradation of weak acids (oxidation by hydroxyl radicals) and $\mathrm{pH}$ of the reaction mixture (Figure 1). In addition, $\mathrm{pH}$ affects also the chromatographic separation as well as detection. Aromatic acids ( $p$-hydroxybenzoic, salicylic, or terephthalic) used as sensors, as well as products of their reaction with hydroxyl radicals, may be separated by reversed phase or ion exclusion chromatography $[8,17,20,21]$. In both cases, the retention increases with the decrease in $\mathrm{pH}$ (dissociation) [22]. On the electrochemical detector the higher peaks (lower detection limit) are obtained for more dissociated acids, that is, at higher $\mathrm{pH}$.

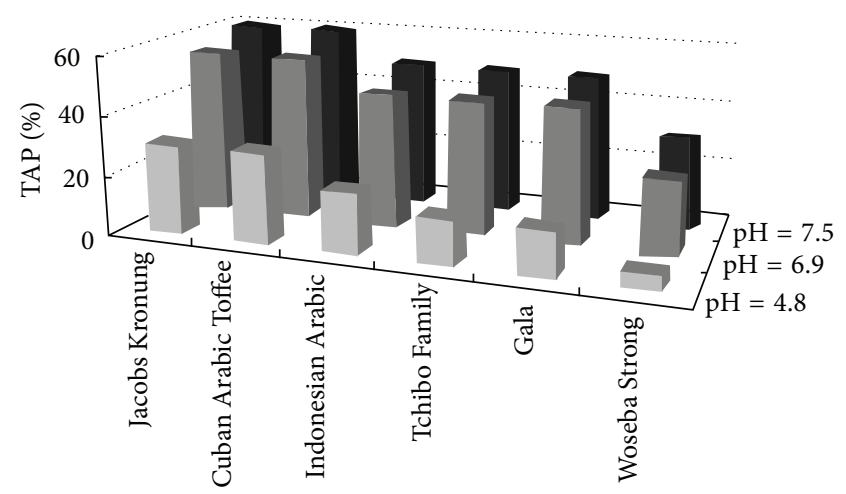

FIGURE 2: TAP values of various coffees at different $\mathrm{pH}$.

The degree of degradation, $S_{D}$, can be expressed as

$$
S_{D}=100-\frac{S^{0}-S^{E}}{S^{0}} \cdot 100[\%],
$$

where $S^{0}$ and $S^{E}$ denote area under chromatographic peaks of the test compound obtained before and after its reaction with hydroxyl radicals, respectively.

It turned out (Figure 1) that the dependence of $S_{D}$ on $\mathrm{pH}$ passes through a maximum value. This is due to the $\mathrm{pH}$ influence on the generation of hydroxyl radicals as well as their reaction with the sample and the sensor. In general, the dissociated and undissociated forms of the compounds react differently with the hydroxyl radicals. TAP values of different types of coffees, obtained at various $\mathrm{pH}$ values, are shown in Figure 2. They were calculated according to the following formula:

$$
\% \mathrm{TAP}=\frac{S_{0}-S}{S_{0}} \cdot 100[\%],
$$

where $S$ and $S_{0}$ denote area under 3,4DHBA peak measured with and without the sample in the reaction mixture, respectively.

The antioxidative properties of coffee are mainly due to polyphenols. The same compounds are toxic in the environment. Both cases (the measurement of the sample antioxidative properties and the oxidation of environmental pollutants) have the same reaction mechanisms-abstraction of hydrogen from hydroxyl groups. It was found that for all tested samples the increase of the $\mathrm{pH}$ value caused the increased of TAP value. This result is useful from the practical point of view. It means that the coffee antioxidants are more reactive in these parts of the human body which are characterized by higher $\mathrm{pH}$, like the mouth or the duodenum. It is worth noting that the proposed assay provides an easy way, contrary to the "classical" methods, to study the effect of $\mathrm{pH}$ on TAP and/or degradation processes.

The influences of concentrations of $\mathrm{Fe}^{2+}, \mathrm{H}_{2} \mathrm{O}_{2}$, and ascorbic acid (AA) on the degradation of $p$-HBA are presented in Figures 3-5, respectively. It has been found that $S_{D}$ has increased by up to $0.2 \mathrm{mM} \mathrm{Fe}^{2+}$. In turn, at higher $\mathrm{H}_{2} \mathrm{O}_{2}$ and AA concentrations the decrease of the $p$-HBA degradation is observed. It should be noted that (1) describes 


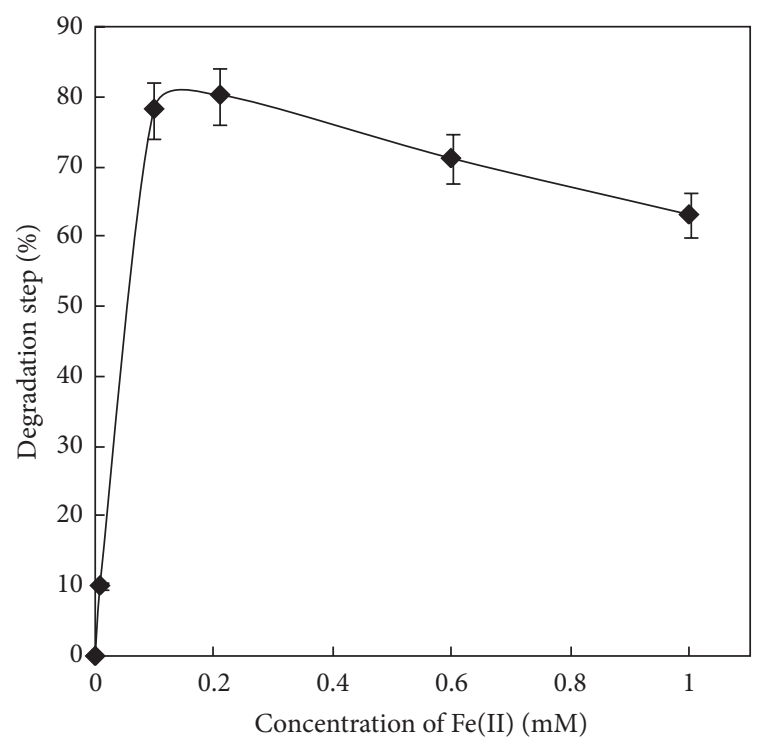

FIGURE 3: Effect of $\mathrm{Fe}^{2+}$ concentration on the step of degradation, $S_{D}$, of $p$-HBA.

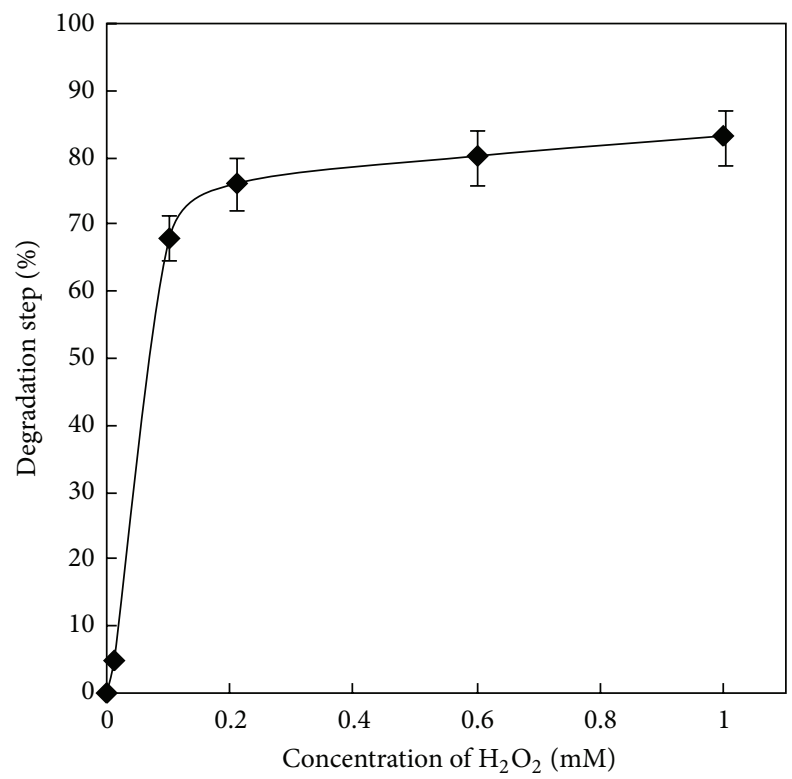

FIGURE 4: Effect of $\mathrm{H}_{2} \mathrm{O}_{2}$ concentration on the step of degradation, $S_{D}$, of $p$-HBA.

the Fenton reaction in a very simplified way. The complexes and hydroxides of iron ions play also an important role in the Fenton reaction [18]. Also $p$-HBA is oxidized in many other side reactions. For example, $\mathrm{Fe}^{3+}$ ions and $\mathrm{H}_{2} \mathrm{O}_{2}$ are oxidizers and they can react with reducing agents in the sample and with the sensor. In turn, the hydroxyl radicals generated by the Fenton reaction, which are very strong oxidants, can also oxidize hydrogen peroxide or $\mathrm{Fe}^{2+}$ ions. Therefore, the nonlinear dependencies, presented in Figures 1-5, are observed. The increasing concentration of hydrogen peroxide (Figure 4) results in the SD increase until the limiting value

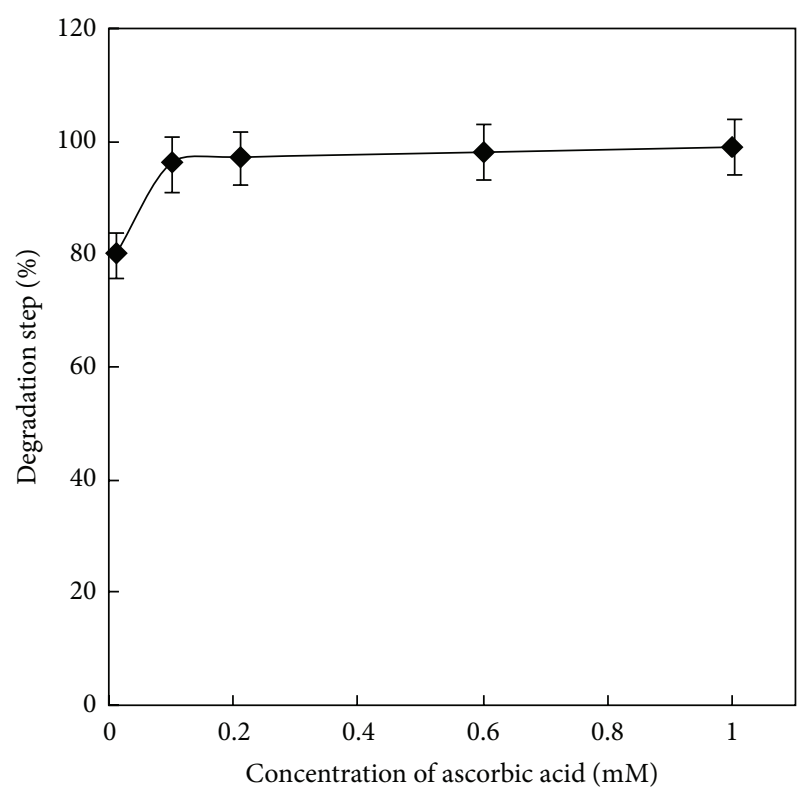

FIGURE 5: Effect of the concentration of ascorbic acid on the step of degradation, $S_{D}$, of $p$-HBA.

is reached. That is why, for further measurements, $1 \mathrm{mM}$ $\mathrm{H}_{2} \mathrm{O}_{2}$ was used. $\mathrm{Fe}^{2+}$ ions are oxidized by $\mathrm{H}_{2} \mathrm{O}_{2}$ to $\mathrm{Fe}^{3+}$ ions. The rate of this reaction increases with the increasing concentration of $\mathrm{Fe}^{2+}$ ions (Figure 3). A similar effect can be obtained by adding a reducing agent (such as adenosine diphosphate, ADP, or ascorbic acid) to the reaction mixture (Figure 5) [18]. Then, the higher concentration of $\mathrm{Fe}^{2+}$ ions is obtained by $\mathrm{Fe}^{3+}$ ions reduction. It turned out that to get nearly $100 \%$ step of the degradation of $p$-HBA, the concentration of ascorbic acid in the reaction mixture is required as low as $0.1 \mathrm{mM}$ (Figure 5).

The polyphenols are widely considered to contribute to health benefits in humans and other living organisms because of their antioxidative properties. However, they are toxic to plants and soil microbes since they participate in the redox reactions in the environment. In particular, substituted phenols are muta- and cancerogenic [23]. Since thousands of tons of antioxidants are consumed each year in the world, a large number of them have been detected in sewage treatment plant effluents, in surface and ground waters and even in drinking water. Therefore, it is so important to elaborate the assay for their degradation, for example, by oxidation. Chromatograms of $p$-HBA and $p$-HBA after its reaction with the hydroxyl radicals, are presented in Figure 6. It turned out that complete degradation of $p$-HBA was obtained after 2 minutes [17]. Although the degradation of other aromatic acids proceeded more slowly, as shown in Figure 7, their degradation time never exceeded 10 minutes (Figure 8).

Polycyclic aromatic hydrocarbons (PAHs) belong to a group of ubiquitous environmental contaminants formed and released during incomplete combustion or by industrial processes. They are characterized by high muta- and/or carcinogenic potential. Therefore, it is strongly recommended to remove them from the environment and food. Time 


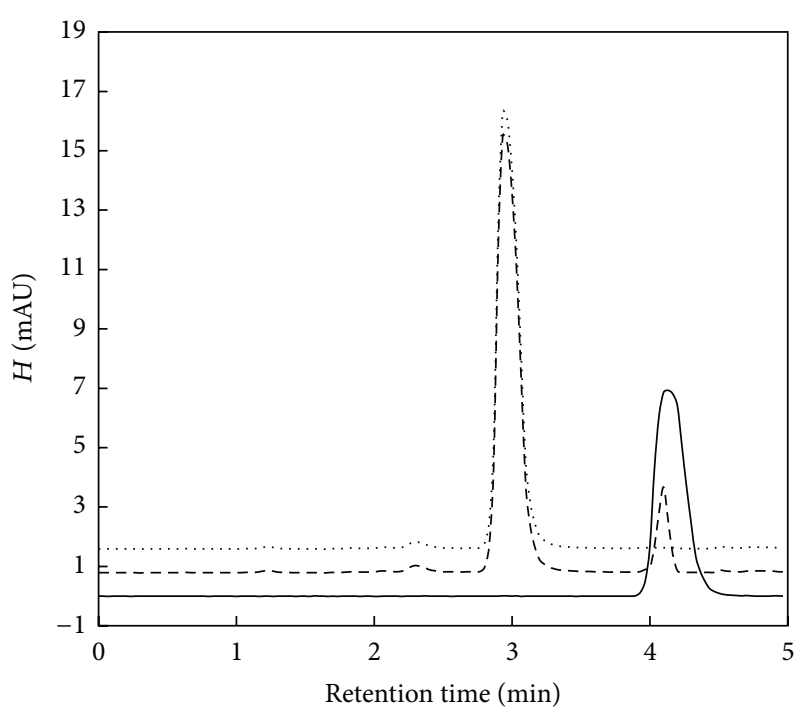

FIgURE 6: HPLC chromatograms of $p$-HBA before (-), after 1 min (---), and $2 \mathrm{~min}(---)$ reaction with the hydroxyl radicals. Reaction conditions: concentration of $\mathrm{H}_{2} \mathrm{O}_{2}, 0.03 \%, \mathrm{Fe}^{2+}, 1 \mathrm{mM}$, and ascorbic acid, $0.1 \mathrm{mM}$. Chromatographic conditions: column, Eurospher C18 $5 \mu \mathrm{m} 250 \times 4 \mathrm{~mm}$ I.D. (Knauer), temperature, $25^{\circ} \mathrm{C}$, mobile phase, phosphate buffer $\mathrm{pH}=6.6$ with 2 vol. $\%$ methanol, flow rate, $1 \mathrm{~mL} \mathrm{~min}^{-1}$, and fluorescence detection with the excitation/emission wavelengths, $270 / 358 \mathrm{~nm}$.

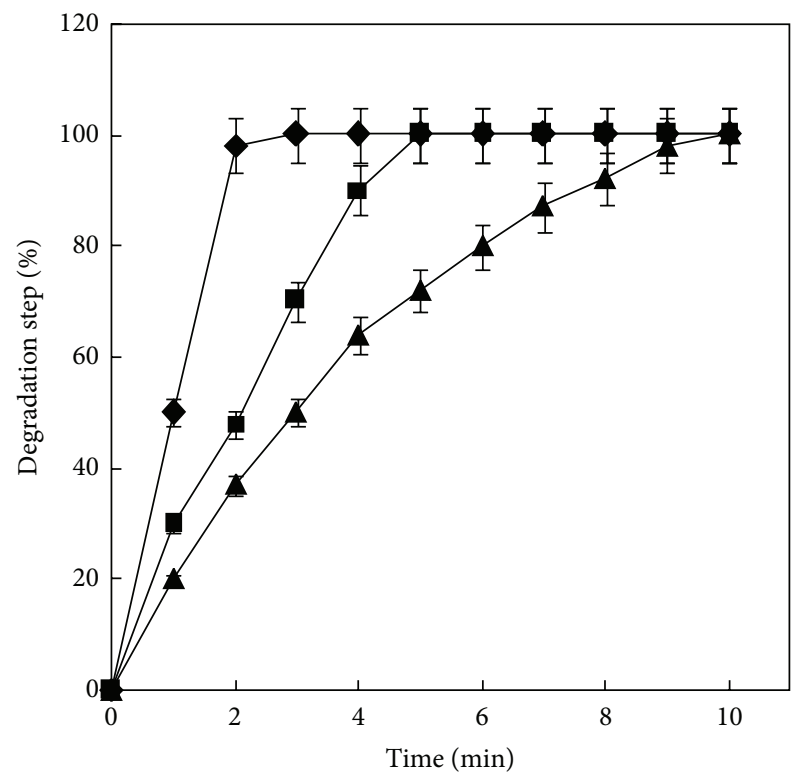

Figure 7: Changes of the degradation steps of ( $)$ p-hydroxybenzoic, ( $\mathbf{\square})$ sulfosalicylic, and ( $\mathbf{\Lambda}) p$-aminobenzenesulphonic acids.

required for their degradation is much longer than that for polyphenols. An example for B[a]P is presented in Figure 9. In this case, the decrease in $\mathrm{pH}$ of the reaction caused an increase in its degradation step only when accelerating the Fenton reaction (without affecting dissociation of the sample). Similar results were obtained for other PAHs.

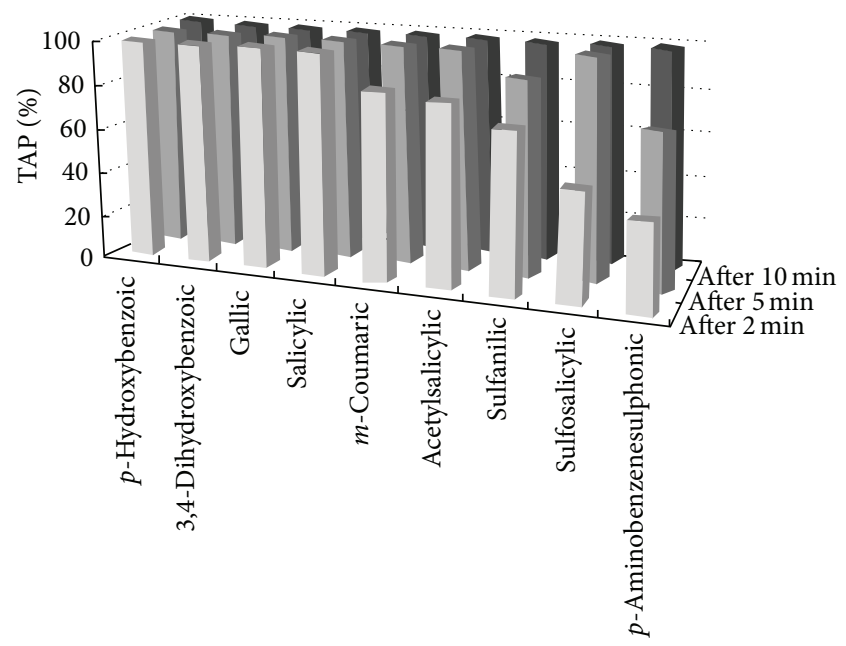

FIgURE 8: The degradation steps of different aromatic acids obtained after different times of their reactions with the hydroxyl radicals.

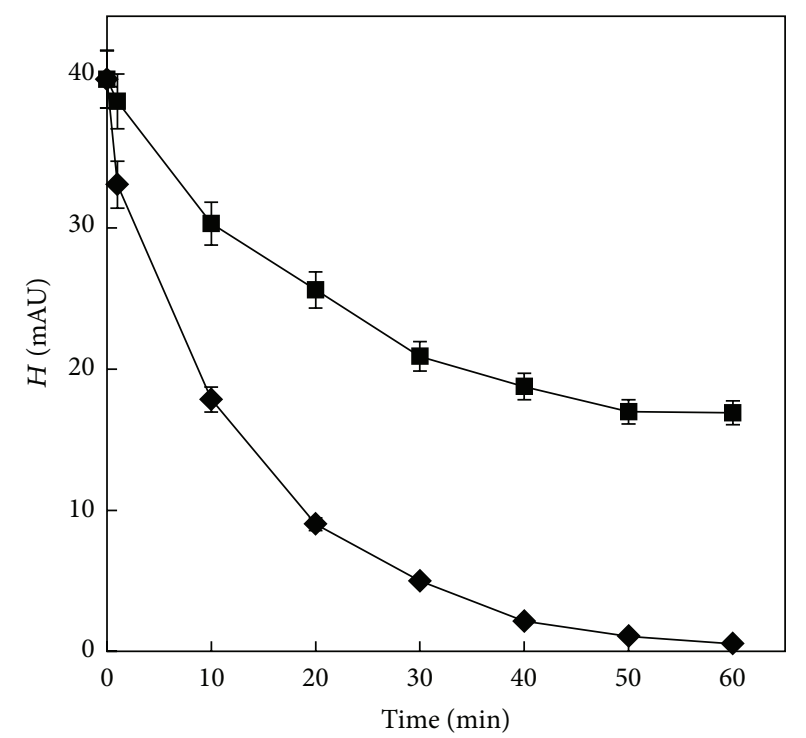

FIGURE 9: Changes of the chromatographic peaks heights (degradation) of $\mathrm{B}[\mathrm{a}] \mathrm{P}$ with time, $(\mathbf{)} \mathrm{pH} 2.7,(\mathbf{\square}) \mathrm{pH} 5.8$.

\section{Conclusions}

The elaborated assay for the measurement of the TAP can be used in studies of degradation of toxic compounds in the environment. It turned out that the hydroxyl radicals, characterized by strong oxidizing properties, can be used for the degradation of phenols and PAHs. The maximum degree of the degradation was obtained for $\mathrm{pH}=3.0$ and $0.1 \mathrm{mM}$ $\mathrm{Fe}^{2+}$.

\section{Conflict of Interests}

The authors declare that there is no conflict of interests regarding the publication of this paper. 


\section{References}

[1] B. Halliwell, "Free radicals, antioxidants, and human disease: curiosity, cause, or consequence?” The Lancet, vol. 344, no. 8924, pp. 721-724, 1994.

[2] P. M. Wood, “The potential diagram for oxygen at $\mathrm{pH}$ 7," Biochemical Journal, vol. 253, no. 1, pp. 287-289, 1988.

[3] R. A. Floyd, "Role of oxygen free radicals in carcinogenesis and brain ischemia," FASEB Journal, vol. 4, no. 9, pp. 2587-2597, 1990.

[4] W. Malinka, M. Kaczmarz, B. Filipek, J. Sapa, and B. K. Głód, "Preparation of novel derivatives of pyridothiazine-1,1-dioxide and their CNS and antioxidant properties," Farmaco, vol. 57, no. 9, pp. 737-746, 2002.

[5] B. K. Głód, G. A. Czapski, and P. R. Haddad, "Application of high-performance liquid chromatography to the investigation of free radical reactions in biological systems," Trends in Analytical Chemistry, vol. 19, no. 8, pp. 492-497, 2000.

[6] R. Amarowicz, A. Troszyńska, N. Baryłko-Pikielna, and F. Shahidi, "Polyphenolics extracts from legume seeds: correlations between total antioxidant activity, total phenolics content, tannins content and astringency," Journal of Food Lipids, vol. 11, no. 4, pp. 278-286, 2004.

[7] G. Polak, M. Koziol-Montewka, M. Gogacz, I. Blaszkowska, and J. Kotarski, "Total antioxidant status of peritoneal fluid in infertile women," European Journal of Obstetrics Gynecology and Reproductive Biology, vol. 94, no. 2, pp. 261-263, 2001.

[8] B. K. Głód, K. I. Stańczak, A. Woźniak, and W. Pakszys, "Determination of catecholamines and the total antioxidant potential of blood plasma by use of an improved RPHPLC-ED assay," Acta Chromatographica, vol. 14, pp. 142-148, 2004.

[9] K. L. Armbrust and D. G. Crosby, "Fate of carbaryl, l-naphthol, and atrazine in seawater," Pacific Science, vol. 45, no. 3, pp. 314320, 1991.

[10] J. A. Garrido, E. Brillas, P. L. Cabot, F. Centellas, C. Arias, and R. M. Rodriguez, "Mineralization of drugs in aqueous medium by advanced oxidation processes," Portugaliae Electrochimica Acta, vol. 25, no. 1, pp. 19-41, 2007.

[11] Y. Deng, K. Zhang, H. Chen et al., "Iron-catalyzed photochemical transformation of benzoic acid in atmospheric liquids: product identification and reaction mechanisms," Atmospheric Environment, vol. 40, no. 20, pp. 3665-3676, 2006.

[12] J. H. Sun, S. P. Sun, M. H. Fan, H. Q. Guo, L. P. Qiao, and R. X. Sun, "A kinetic study on the degradation of $p$-nitroaniline by Fenton oxidation process," Journal of Hazardous Materials, vol. 148, no. 1-2, pp. 172-177, 2007.

[13] F. J. Rivas, F. Beltrán, O. Gimeno, and F. Carvalho, "Fenton-like oxidation of landfill leachate," Journal of Environmental Science and Health A, vol. 38, no. 2, pp. 371-379, 2003.

[14] J. Yoon, S. Cho, Y. Cho, and S. Kim, "The characteristics of coagulation of Fenton reaction in the removal of landfill leachate organics," Water Science and Technology, vol. 38, no. 2, pp. 209-214, 1998.

[15] J. J. Pignatello, "Dark and photoassisted $\mathrm{Fe}^{3+}$-catalyzed degradation of chlorophenoxy herbicides by hydrogen peroxide," Environmental Science and Technology, vol. 26, no. 5, pp. 944951, 1992.

[16] J. Prousek, "Advanced oxidation processes for water treatment. Chemical processes," Chemicke Listy, vol. 90, no. 4, pp. 229-237, 1996.
[17] P. Wantusiak and B. K. Głód, "Application of UV detection in HPLC in the total antioxidant potential assay," Central European Journal of Chemistry, vol. 10, no. 6, pp. 1786-1790, 2012.

[18] B. K. Głód, K. Kaczmarski, and M. H. Baumann, "Application of mass spectrometry to the determination of total antioxidant potential," Chemia Analityczna, vol. 51, no. 1, pp. 51-64, 2006.

[19] A. Simić, D. Manojlović, D. Šegan, and M. Todorović, "Electrochemical behavior and antioxidant and prooxidant activity of natural phenolics," Molecules, vol. 12, no. 10, pp. 2327-2340, 2007.

[20] B. K. Głód, P. Piszcz, K. Czajka, and P. K. Zarzycki, "A new total antioxidant potential measurements using RP-HPLC assay with fluorescence detection," Journal of Chromatographic Science, vol. 49, no. 5, pp. 401-404, 2011.

[21] B. K. Głód, P. Piszcz, I. Kiersztyn, A. Lamert, and P. K. Zarzycki, "Application of HPLC assay to the measuraments of total antioxidant potential, free radicals and antioxidants," Camera Separatoria, vol. 1, pp. 41-66, 2009.

[22] K. L. Ng, B. K. Glód, G. W. Dicinoski, and P. R. Haddad, "Retention modelling of electrostatic and adsorption effects of aliphatic and aromatic carboxylic acids in ion-exclusion chromatography-II. Calculations of adsorption coefficients in unbuffered eluents," Journal of Chromatography A, vol. 920, no. 1-2, pp. 41-49, 2001.

[23] S. Azam, N. Hadi, N. U. Khan, and S. M. Hadi, "Prooxidant property of green tea polyphenols epicatechin and epigallocatechin-3-gallate: implications for anticancer properties," Toxicology in Vitro, vol. 18, no. 5, pp. 555-561, 2004. 

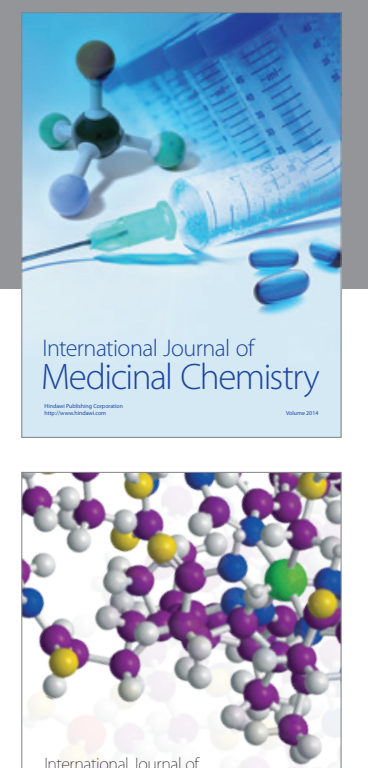

\section{Carbohydrate} Chemistry

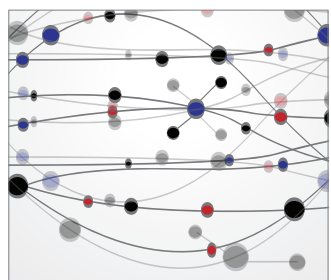

The Scientific World Journal
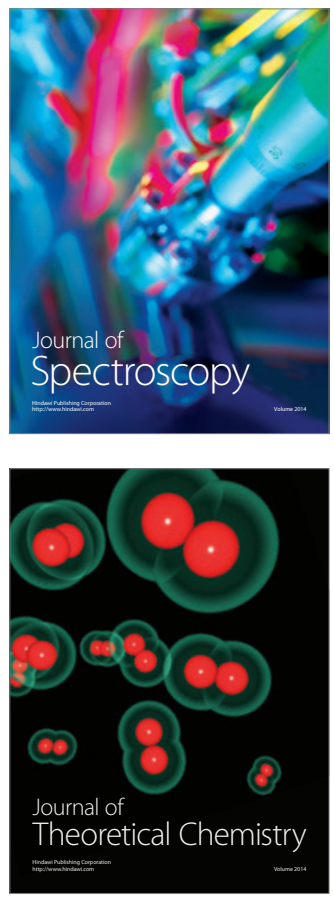
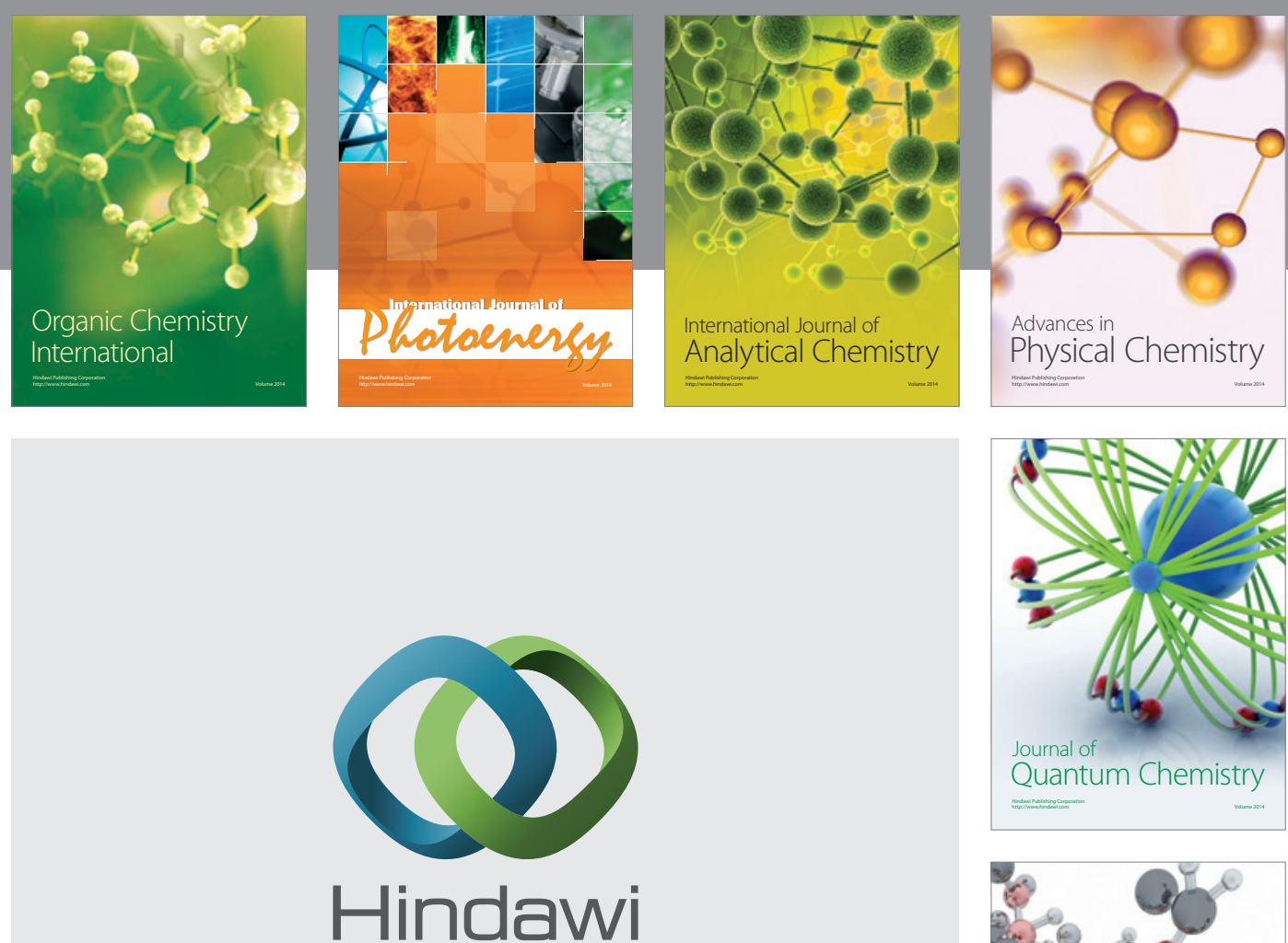

Submit your manuscripts at

http://www.hindawi.com

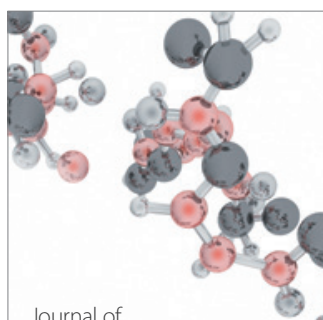

Analytical Methods

in Chemistry

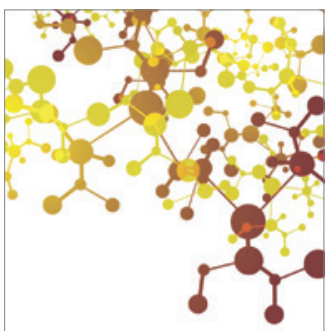

Journal of

Applied Chemistry

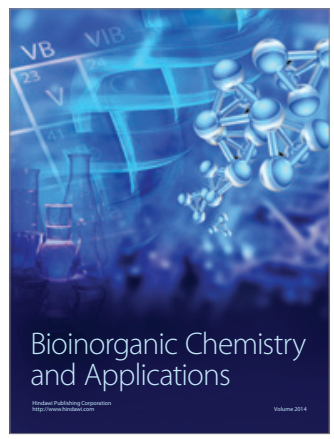

Inorganic Chemistry
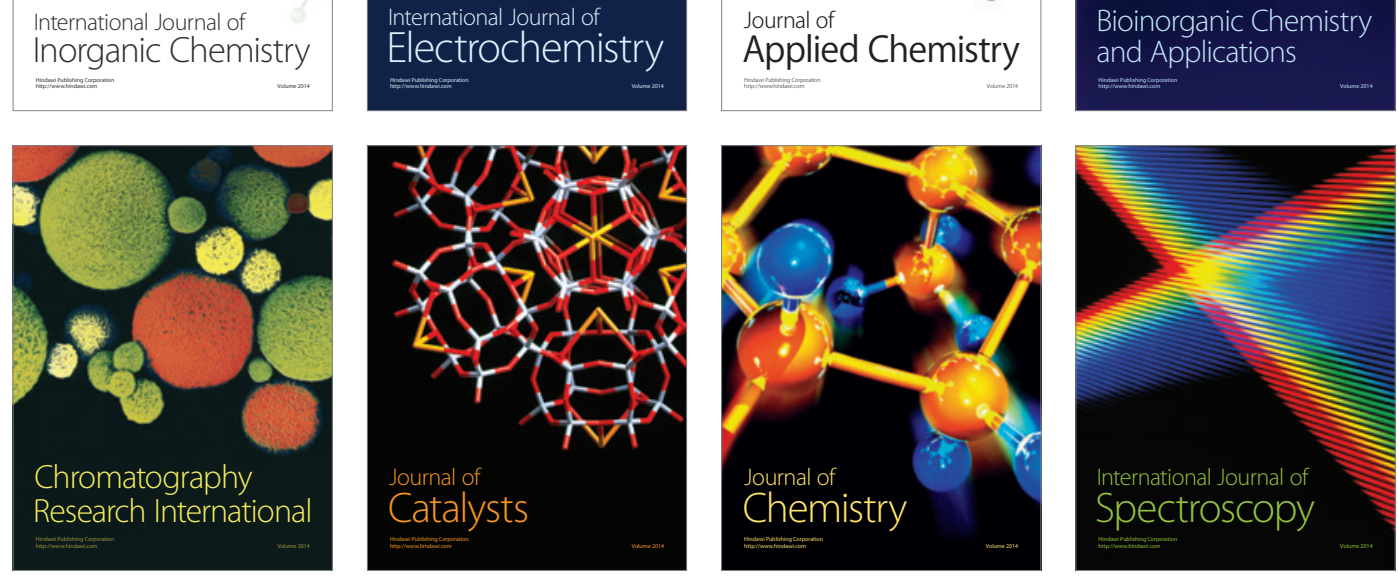